\title{
Sobre cheques y normas penales en conflicto. Balance de Discusiones 9 (2009)
}

\author{
On Checks and Conflicting Criminal Norms. \\ Taking Stock of Discusiones 9 (2009)
}

Santiago Roldán*

Recepción: 16/04/2018

Evaluación: 07/06/2018

Aceptación final: 14/07/2018

\begin{abstract}
Resumen: El texto retoma el debate dado en Discusiones 9 alrededor del artículo de Juan Pablo Alonso "Normas penales y conflicto de deberes". Tras presentar brevemente los argumentos del autor, analizo algunas ramificaciones de los temas tratados en aquella polémica y las distribuyo según se refieran a la parte especial del derecho penal, a su parte general o la Teoría general del derecho.
\end{abstract}

Palabras claves: delitos, derecho penal, conflicto de deberes, contradicciones normativas

\begin{abstract}
This essay tackles the debate generated in Discusiones 9 around Juan Pablo Alonso's "Normas penales y conflicto de deberes". After briefly introducing the author's arguments, I analyze some ramifications of the subjects that were addressed in that controversy. I distribute them depending on their relation to the special part of criminal law theory, the general part of criminal law theory, or the legal theory.

Key-words: crimes, criminal law, conflict of duties, contradictory norms

Abogado y doctorando (Universidad Nacional de Buenos Aires). Correo electrónico: santirolo@hotmail.com. Agradezco los comentarios de la árbitra o el árbitro anónimo y los siempre atinados consejos de Gustavo Beade.
\end{abstract}




\section{Introducción}

El artículo "Normas penales y conflicto de deberes" de Juan Pablo Alonso ${ }^{1}$ (en adelante NP), sobre el cual giró el número 9 de la revista Discusiones (2009), tiene un atractivo particular. El autor utiliza un acercamiento analítico, generado en el ámbito de la Teoría general del derecho, con el fin de iluminar un problema concreto del derecho penal, más precisamente, la interacción de dos figuras delictivas del código penal argentino. Y esta confluencia explícita de saberes no es algo que se vea todos los días.

No es mi intención reproducir el debate del que participaron Iñigo Ortíz de Urbina Gimeno, Luis Duarte d'Almeida, Alejandra Verde y José Milton Peralta, y las respuestas dadas por el propio Alonso; para introducirse en él nada mejor que la insuperable presentación de Hernán Bouvier al número 9 de la revista y los textos que la componen. Tampoco intentaré dirimir aquella discusión, sino más bien presentar una serie ramificaciones nacidas de aquel debate que cruzan diversas áreas del derecho y merecen seguir siendo pensadas.

Luego de resumir el texto de Alonso, tomaré un camino distinto del usual y partiré de lo más puntual para finalizar en lo más general, es decir, desde la parte especial del derecho penal pasaré a su parte general, para terminar en la Teoría general del derecho.

\section{2. "Normas penales y conflictos de deberes"}

El texto de Alonso se centra en un conflicto que podría darse entre dos delitos contenidos en el Código Penal Argentino: el llamado libramiento de cheques $\sin$ fondos (art. 302, inciso $1^{\circ}$ ) y la quiebra fraudulenta (art. 176, inc. 3). El caso que concentra la atención de Alonso es el siguiente: una persona libra un cheque común que es rechazado por carecer de fondos en la cuenta, ante lo cual resulta intimado al pago, pero esto último ocurre luego de que el librador se presentó en concurso preventivo o fue declarado 
Sobre cheques y normas penales en conflicto. Balance de Discusiones 9 (2009)

en quiebra. Ante dicha situación ¿el librador debe o no pagar el cheque? En su caso, ¿qué debe fallar un juez penal que analiza tal comportamiento?

Las formulaciones normativas con las que Alonso comienza su análisis son el art. 302, inciso $1^{\circ}$, y el art. 176, inciso 3. En lo que aquí importa, en el primero se establece una sanción de prisión e inhabilitación para el que "dé en pago... un cheque sin tener provisión de fondos... y no lo abonare... dentro de las veinticuatro horas de habérsele comunicado la falta de pago mediante... forma documentada de interpelación".

Según el 176, inciso $3^{\circ}$, “[s] erá reprimido, como quebrado fraudulento, con prisión...e inhabilitación..., el comerciante declarado en quiebra que, en fraude de sus acreedores, hubiere... [concedido] ventajas indebidas a cualquier acreedor".

Para Alonso, si la persona paga el cheque otorgará una ventaja indebida a un acreedor al no respetar el procedimiento, los plazos y las condiciones del proceso de concurso o quiebra (en otras palabras, no respetará la pars conditio creditorum); sin embargo, si elige no hacerlo, habrá librado un cheque sin fondos sin haberlo pagado al ser intimado.

Alonso utiliza este caso para analizar una situación patológica entre lo que identifica como el "sistema del juez o sistema primario" y el "sistema del ciudadano o sistema secundario" a la luz de las normas que extrae de los artículos 176, inciso 3, y art. 302, inciso 1, del código penal ${ }^{2}$. A partir de las nociones de norma primaria y secundaria de Kelsen, llamará "sistema del juez o primario" al conjunto de normas que regulan la actividad sancionatoria de aquél y, "sistema del ciudadano o secundario", al conjunto de normas que regulan la conducta de las personas. Para Alonso, el sistema primario conformado por tales normas es completo y consistente y el juez deberá sancionar cualquiera sea la decisión del ciudadano; solo cambiará la figura delictiva aplicable: utilizará el art. 302 si el sujeto no paga el cheque y si lo hace, el art. 176, inciso, 3. No obstante, remarca el autor, si se mira la situación desde la óptica del ciudadano, se verá que de ambos artículos

2 Es importante tener en cuenta que su análisis se limita a esas dos normas, pues el caso podría ser encuadrado en el inciso $2^{\circ}$ del art. 302 CP (véase Peralta, J.M., "Acerca de la función de las escalas penales, las consecuencias de una contradicción normativa y la responsabilidad en virtud de la actio illicita in causa”, Discusiones, 9, 2009, pp. 156-158). 
se derivan normas (secundarias) contradictorias: la persona no debe pagar el cheque porque incurriría en el delito quiebra fraudulenta y debe pagarlo porque de lo contario cometería el delito previsto en el 302, inciso 1. Por tal motivo, el sistema secundario presenta una contradicción normativa: un conflicto entre deberes jurídico-penales que no pueden satisfacerse simultáneamente ${ }^{3}$.

Según Alonso, podría sostenerse que, no obstante la no conflictividad del sistema primario, “...el juez no puede ignorar la conflictividad del sistema secundario; dicho de otra forma, al momento de dictar sentencia, el juez debe atenerse a todas las circunstancias normativas (primarias y secundarias) que se relacionan con la conducta que está juzgando"4. Ello abriría el siguiente espectro de alternativas normativas: (1) la condena bajo cualquier supuesto, (2) la condena bajo un supuesto y la absolución bajo el otro, dependiendo de que prevalezca el delito del art. 176 frente al del art. 302 (condena en caso de pagar el cheque y absolución en caso de no pagarlo), o al revés (condena por no pagar el cheque y absolución por pagarlo), y (3) la absolución bajo cualquier supuesto.

Alonso descarta la primera opción. En su opinión, condenar tanto si se paga como si no implicaría aceptar la derivación de una nueva norma según la cual "[s]i es un deudor sujeto a las reglas concursales que libró un cheque que fuera rechazado sin fondos e intimado de pago, es obligatorio imponer una sanción penal" (desde el punto del sistema primario del juez) o "[e]stá prohibido estar intimado al pago de un cheque rechazado sin fondos estando sujeto a las reglas concursales" (visto como norma secundaria dirigida al ciudadano), y tal solución le resulta improcedente por varias razones. La primera es que el nuevo delito torna "indominable para el agente una acción que en los tipos de origen es dominable”: el pago del cheque. Alonso recuerda que la doctrina penal es relativamente unánime

3 Como dice Alonso siguiendo la caracterización de Alf Ross, se trata de una inconsistencia fáctica "parcial - parcial", pues cada una de las normas en juego tiene un campo de aplicación en el que no se produce conflicto, de modo que la intersección es sólo parcial. Ante un determinado caso, ambas normas regulan la acción "pagar el cheque rechazado" de manera deónticamente incompatible: una (el art. 302) obliga a pagar el cheque y la otra (el art. 176) prohíbe hacerlo (NP, p. 35) 
en sostener que un elemento indominable no puede ser imputado (en la tipicidad objetiva) y si bien reconoce que aquello suele decirse respecto de casos en los que la indominabilidad se debe a razones fácticas, nada obsta, en su opinión, a que tal falta de dominabilidad se presente por razones normativas. A su vez, considera la propuesta de sancionar en todos los casos atentaría contra el principio de legalidad por no encontrarse descripta la conducta prohibida en una norma penal explícitamente formulada. Por último, rechaza la afirmación de que el sistema secundario es irrelevante para el juez y que éste debe guiarse, exclusivamente, por los lineamientos normativos del sistema primario, pues:

El derecho penal evalúa conductas humanas con el objeto de determinar la procedencia de una sanción penal; frente a una acción típica el juez debe evaluar las razones, circunstancias y condicionantes que llevaron al agente a obrar del modo en que lo hizo ${ }^{5}$.

Descartada por improcedente la primera opción, debe determinarse cuál es del deber jerárquicamente superior y corresponderá sancionar únicamente cuando la persona lo haya infringido. Esto lo introduce a la segunda posible alternativa normativa: la condena bajo un supuesto y la absolución bajo el otro.

Un primer modo de intentar establecer una diferente jerarquía entre los deberes, dice Alonso, es analizar las penas atribuidas a cada delito y, a partir de allí, establecer cuál es el instituto tutelado más fuertemente ${ }^{6}$. Sin embargo, descarta este método. Aun en el caso de afirmarse que el delito del art. 176 tiene prevista una sanción mayor que la del art. 302, y que por lo tanto debe cumplirse con el deber jurídico de respetar la pars conditio creditorum,

no puede afirmarse que "no matar" es más importante que "no dañar el patrimonio" porque el primero está penado más severamente que el segundo, sino lo contrario: porque la vida es más

5 NP, pp. 47-48.

6 NP, p. 50. 
Santiago Roldán

importante que el patrimonio es que "matar" tiene mayor pena que “dañar el patrimonio"... 7 .

Además, agrega Alonso, las diferentes escalas atribuidas a los delitos pueden tener otras justificaciones, por ejemplo, que ellas reflejen un distinto modo de comisión que hagan más grave el comportamiento o que la menor sanción pude deberse a que existen protecciones no penales de importancia ${ }^{8}$.

A lo anterior Alonso suma el dato de que las diferencias entre los marcos penales de los delitos analizados no son significativas en su opinión (art. 176: prisión de 2 a 6 años e inhabilitación especial de 3 a 10, y art. 302: prisión de 6 meses a 4 años e inhabilitación especial de 1 a 5). Considera que se tratan de escalas de "relativa equivalencia" por lo que parecería que lo determinante tendrían que ser razones independientes a ellas. Sin embargo, Alonso no encuentra argumentos que diriman el conflicto pues, sostiene, intuitivamente podría afirmarse que el régimen de quiebra prevalece al del cheque porque el primero es un proceso universal, donde todos los acreedores concurren en pie de igualdad, y que la ley de Concursos y Quiebras no establece privilegios para tenedores de cheques, al punto tal que hasta los acreedores más privilegiados (como los que tienen garantías hipotecarias) deben sujetarse a tal régimen. Como contrapartida, el delito de cheque tutela la fe pública, puntualmente, la previsibilidad y fiabilidad del mercado financiero de títulos circulatorios y sucedáneos de la moneda de curso legal, y por tal motivo es improcedente comparar ambos delitos pues "[so]n bienes jurídicos distintos que apuntan hacia principios distintos (la propiedad, por un lado; el libre mercado, por el otro) y es difícil, [si no]...imposible, determinar cuál de ellos debe prevalecer en desmedro de otro" 10 .

7 NP, p. 51. Véase la crítica que Peralta le formula a esta afirmación, en Peralta, J.M., op. cit., pp. 133-140, crítica que Alonso estima acertada (Alonso, J.P., "Respuesta a las críticas", Discusiones, 9, 2009, p. 174).

8 NP, p. 51.

9 NP, p. 52. 
Ante la imposibilidad de determinar qué deber jurídico prevalece y cuál cede, Alonso analiza y defiende la tercera alternativa de solución: absolver en todos los casos, es decir, no condenar tanto si se cancela el cheque luego de la intimación, como si no se lo hace. Esta alternativa le parece la adecuada porque el agente que se encuentre ante esta situación de conflicto entre el deber de pagar el cheque y el deber de no pagarlo, nunca obraría antijurídicamente por haber actuado en cumplimiento de un deber. En definitiva, cualquiera sea el camino que el sujeto siga, su elección no podrá ser objeto de sanción penal. Hasta aquí el texto de Alonso.

\section{Parte especial del derecho penal y el artículo 302, inc. $1^{\circ}$, del CP}

En la llamada parte especial del derecho penal se estudian los elementos que caracterizan a las distintas clases de delitos o figuras delictivas; ese análisis puede ser hecho en un plano prescriptivo (normativo) o en uno descriptivo. En el primero de lo que se trata es de establecer y fundamentar qué tipo de comportamientos deberían ser considerados delitos (y qué penas merecen o es necesario que reciban), mientras que en el segundo lo estudiado son las figuras penales que contiene un determinado ordenamiento jurídico, por ejemplo, los delitos previstos en el Código Penal Argentino. No sería extraño encontrar desacoples entre ambos planos tales como que un concreto sistema jurídico no contemple como delito un comportamiento que desde el punto de vista normativo debiera serlo o, viceversa, que una legislación trate como delictivo una conducta que no debería serlo desde el punto de vista normativo.

El trabajo de Alonso se ubica en este segundo plano, es decir, en el descriptivo, y no deja de ser notable que la figura central sobre la que reposa su atención sea el delito conocido como "libramiento de cheques sin fondos" (art. 302, inciso $1^{\circ}, \mathrm{CP}$ ). Pocos delitos son tan subestimados por lucir como una infracción menor de la que apenas podría justificarse su inclusión en un código penal y, además, bajo una sanción de prisión de un máximo de 4 años, como sucede en el Código Penal Argentino. Ello se trasluce, por

ejemplo, en la siguiente cita de un conocido manual de derecho penal: 
Santiago Roldán

Si prescindimos del código y de las leyes penales y lanzamos una pregunta indiscreta a la realidad social, no necesitamos mucha penetración para percatarnos de que entre la conducta de quien libra un cheque sin provisión de fondos y la de quien golpea una mujer y la viola, no hay nada en común, es decir, que se trata de dos acciones con significado social completamente distinto. Lo único común entre esas conductas es que ambas están previstas en la ley penal... ${ }^{11}$.

Del mismo modo, no resulta aventurado decir que se trata de una figura delictiva que despierta desgano entre los integrantes del sistema judicial: en un ámbito donde los recursos para investigar y juzgar delitos son escasos, pareciera que los esfuerzos tendrían que ser puestos en otro lado. Sin embargo, pocas figuras han generado tanta cantidad de controversias a nivel jurisprudencial como el delito de "cheques sin fondos". Muestra de ello son la cantidad de plenarios que lo han tenido por objeto. La Cámara en lo Criminal y Correccional dictó los plenarios "Alhadeff” (1957), "Seni” (31/5/1960) y Ganapol (13/8/1964), y la Cámara Nacional en lo Penal Económico los plenarios "Gerlero" (6/5/1966), “Crivelli” (20/10/1967), “Silenzi” (09/8/1968), "Walas” (27/11/1968) e "Hidalgo del Castillo" $(20 / 12 / 1968)^{12}$. Hasta la propia Corte Suprema de Justicia de la Nación lidió varias veces con él, como se puede apreciar en el recuento que hace el Procurador General en el dictamen del fallo "Quiroga de Maiolo" (Fallos 293:115). Pero quizá lo más representativo sea la jurisprudencia plenaria dictada por la Cámara Federal de Casación Penal. Este tribunal ha dictado, hasta el momento, catorce plenarios y solo tres de ellos se refieren a la parte especial del derecho penal. ¿Cuál o cuáles fueron los delitos

${ }^{11}$ Zaffaroni, E.R., Manual de Derecho Penal. Parte General, Buenos Aires, Ediar, 1999, p. 21. También, Laporta, M.H., "El Dolo y su determinación en Casación. Normatización y ubicación estructural en una concepción personal del injusto", Lexis Nexis, 2007, p. 77, nota 1: El delito de pago con cheque sin provisión de fondos es "....un delito de cuestionable legitimidad penal, puesto que genera muchas dudas su confronte con..., por un lado, la regla que impide el establecimiento de prisión por deudas...; y por otro, el principio de subsidiariedad y carácter fragmentario del Derecho Penal..." (también, pp. 81-82).

12 Incluso en una oportunidad la cámara fue convocada para fijar doctrina sobre el caso planteado en NP en la variante de la convocatoria de acreedores, sin embargo el tribunal no dictó doctrina plenaria porque para la mayoría de los jueces no estaban reunidos los presupuestos procesales necesarios (Cámara Nacional en lo Penal Económico, "Perotti", 9/02/1973). 
Sobre cheques y normas penales en conflicto. Balance de Discusiones 9 (2009)

estudiados? Los tres se refieren al art. 302 del Código Penal. Hablo de los plenarios "Jalile" (13/12/1996), "Iriart" (30/9/2003) y "Pereyra" (25/7/2005).

Otro aspecto llamativo es que si bien la figura de libramiento de cheques sin fondos está prevista en la versión original de nuestro código penal (1921), contando incluso con antecedentes más antiguos, ha generado discusiones que sólo de manera reciente han sido atendidas por los juristas dedicados a la parte general del derecho penal. Doy dos ejemplos.

$\mathrm{Al}$ igual que los debates actuales en torno a los delitos medio ambientales y la legitimidad de los "delitos de daño acumulativo" 13 , la problemática que encierra esa clase de figuras ya se encontraba presente en el delito de libramiento de cheques sin fondos. Se afirma que lo protegido es la fe pública respecto al funcionamiento del cheques como instrumento en la vida económica y patrimonial, sin embargo, es claro que el libramiento de un cheque sin fondos no pone en jaque el funcionamiento de la institución "cheque" como papel de comercio en la vida social, sino que es la repetición de tal actuar lo que provocaría la desconfianza en las personas y, como consecuencia, su falta de funcionamiento en los hechos (que la economía necesite de un instrumento como el cheque y que su utilización deba estar respaldada con el derecho penal es otra discusión). El otro ejemplo se refiere al dolo y los supuestos de ceguera ante los hechos o desconocimiento deliberado ${ }^{14}$. El tema ya se planteaba en aquellos casos en los cuales quien libraba un cheque sin fondos se las ingeniaba para "no recibir o no tomar conocimiento" de la comunicación que le pudiera ser dirigida como intimación para su pago ${ }^{15}$.

${ }^{13}$ Con ello se hace alusión a que una única realización del delito (por ejemplo, verter residuos tóxicos al cauce de un rio) o bien no produce una afectación al medio ambiente, o bien no lo hace de una manera notoria, sino que es su comisión repetida por diversas personas lo que realmente lo perjudica y se busca en definitiva evitar. Ello genera la pregunta de si esta clase de figuras respeta el principio de daño, el principio de proporcionalidad (entre la gravedad del concreto hecho y la sanción) y el de culpabilidad (responsabilidad por el hecho propio - proscripción de la responsabilidad por el hecho de un tercero)-. Véase Alcácer Guirao, R., "La protección del futuro y los daños cumulativos", RECPC, 04-08, 2002, p. 20.

${ }^{14}$ Sobre todo esto puede verse el número 12 de Discusiones, "Ignorancia deliberada y Derecho Penal".

15 Véase CN Penal Económico, Sala III, “Arribas de Santos” Reg. 191/1986, rta. el 26/6/1986. Véase también el plenario "Iriart" de la CN Casación Penal. Un análisis más detallado en Laporta, op. cit. 
Por toda esta serie de controversias no debería sorprender que un número de la revista Discusiones se haya centrado en el delito de libramiento de cheques sin fondos. El art. 302 del Código Penal ha generado muchos debates y estos, tal como acontece con el caso tratado en el artículo de Alonso, exigen que se los siga estudiando aún. Valga como muestra la siguiente cuestión, que recién aparecerá aludida por Alonso en las últimas páginas del debate.

\section{a) Ventajas indebidas y pagos autorizados}

En su respuesta a la crítica de Ortíz de Urbina Gimeno (y también de Peralta) respecto a que era claro que el deber de no pagar el cheque era mayor al de hacerlo, pues la pena prevista en el art. 176, inc. 3, es más grave que la del 302, inciso 1, Alonso afirma que el delito de quiebra fraudulenta requiere, en su tipo penal, que se concedan ventajas "indebidas" a cualquier acreedor por lo que, de manera previa a analizar las escalas penales, debería elucidarse si pagar un cheque ante la intimación por su rechazo no era en rigor un "pago debido"16.

Alonso señala algo importante: el texto del artículo 176, inc. 3, alude a las "ventajas indebidas", por lo que se sobreentiende que el sistema jurídico admitiría ciertos pagos (los que son "debidos" o al menos autorizados) a pesar de la situación patrimonial en que se encuentra el deudor ${ }^{17}$. Uno podría pensar que expresiones que contienen algunas formulaciones legales de delitos, como "indebida" en el 176, o el "ilegalmente" del art. 141 del CP (privación de la libertad) o similares, son o funcionan como una alusión redundante a las causales de justificación que podrían tener por autorizado un comportamiento que de otro modo estaría prohibido (por ejemplo, un estado de necesidad o una legítima defensa), pero lo más usual es que tales alusiones hagan referencia a las leyes que reglamentan los instrumentos o institutos del derecho que están involucrados en el caso o a

${ }^{16} \mathrm{NP}, \mathrm{pp} .170$ y 176.

${ }^{17}$ De hecho, Duarte d'Almeida había sugerido que el caso trabajado por Alonso podía resuelto por medio de una interpretación adecuada del adjetivo "indebida" contenido en art. 176, inc. 3 (Duarte d'Almeida, L., "Deberes Jurídicos, Teoría del Derecho y Dogmática Penal”, Discusiones, 9, 2009, p. 109). 
Sobre cheques y normas penales en conflicto. Balance de Discusiones 9 (2009)

autorizaciones estatales para llevar a cabo determinadas actividades sujetas a fiscalización ${ }^{18}$. En el caso que nos ocupa, el giro utilizado en art. 176, inc. c, nos remite al régimen legal de los concursos y quiebras y a la legislación que regula la utilización de los cheques. Acaso el conflicto que existe entre los intereses del receptor del cheque (que se lo paguen) y el del resto de los acreedores del librador (que el monto del cheque forme parte del activo del concurso o la quiebra), ya se encuentre regulado por fuera de las leyes penales estrictamente hablando.

Por ejemplo, eso era lo que sucedía con cuando regía el decreto-ley $4776 / 63$ (modificado por las leyes 16.613 y 23.549). En su artículo 34 establecía: "El banco girado debe pagar el cheque inmediatamente a su presentación; pero se negará a pagarlo... [c] uando el banco tuviese conocimiento de que el librador fue declarado en quiebra o en concurso civil con anterioridad a la fecha de su emisión...."

A partir de ese artículo no era difícil concluir, mediante un argumento a contrario, que el cheque presentado al cobro debía ser pagado por el banco girado siempre que haya sido librado con anterioridad al concurso o la declaración de quiebra ${ }^{19}$. Si eso era así, lo mismo podía concluirse, argumento a simile mediante, para el caso de que la cuenta careciera de fondos $y$, ante el rechazo, el tomador del cheque intimara su pago documentalmente: si el librador tenía el dinero en efectivo debía cancelar el cheque sin que pudiera ampararse en el inicio de un procedimiento concursal o la declaración de quiebra ${ }^{20}$. Todo ello generaba la consecuencia de que, en rigor, el monto por el cual se libraba el cheque ya no podía ser contabilizado como parte del patrimonio del deudor que constituía la garantía o prenda común del resto de los acreedores.

El régimen del decreto ley 4776/63 fue derogado por la ley 24.452 , que estableció una nueva reglamentación (Ley de cheques). En el artículo 34 ya no se lee la aclaración sobre los concursos y quiebras y únicamente se consigna que el banco se negará a pagar un cheque "en los casos estable-

${ }^{18}$ Roxin, C., Derecho Penal, Parte General, Tomo I, Fundamentos, La estructura de la Teoría del Delito, Madrid, Civitas, 1997, $\$ \$ 10$ y 30-33, pp. 291-292.

${ }^{19}$ Fontanarrosa, R.O., Régimen Jurídico del Cheque, Buenos Aires, Zavalía, 1986, pp. 77 y 146.

${ }^{20}$ Bergel, S.D., "Convocatoria de acreedores y delito de cheques sin provisión de fondos", ED, 33, 1970, pp. 807-808. 
cidos en esta ley o en su reglamentación". Bajo esa redacción ya no queda tan claro si el banco debe pagar o no el cheque librado con anterioridad del concurso o la declaración en quiebra. Pero en la dirección contraria, ahora tampoco lo es si el banco no debiera pagar los cheques librados incluso después de abierto el concurso o decretada la quiebra. En esa dirección, por ejemplo, corre el artículo 54 de la ley cuando establece que los cheques de pago diferido son oponibles a concursos y quiebras. Paralelamente, lo que funciona como régimen general es lo establecido por la ley de Concursos y Quiebras (24.522). En lo que respecta a la quiebra, con su declaración “[e] 1 fallido queda desapoderado de pleno derecho de sus bienes existentes a la fecha de la declaración...y de los que adquiriera hasta su rehabilitación. El desapoderamiento impide que ejercite los derechos de disposición y administración" (art. 107) y los pagos que hiciera el fallido serían pasible de ser declarados ineficaces (arts. 109 y 119). No ocurre lo mismo con el concursado, pues la persona conserva la administración de su patrimonio y podría llegar a pagar un cheque ante su intimación. Sin embargo, esa administración se encuentra bajo vigilancia del síndico e incluye la prohibición de realizar ciertos actos (arts. 15 y 16). Al margen de ello, lo anterior debe ser analizado a la luz del régimen de privilegios contenidos en esa ley (Título IV, capítulo I) y las disposiciones pertinentes del nuevo Código Civil y Comercial de la Nación (Capítulos 1 y 2 del título II del libro sexto).

Todas estas cuestiones podrían seguir debatiéndose por especialistas en derecho comercial a los fines de establecer si el pago de un cheque librado previo al concurso o a la quiebra constituiría o no un pago "debido" en los términos del art. 176, inc. 3, del $\mathrm{CP}^{21}$. En todo caso, lo que queda de enseñanza para los penalistas es aquello que una vez le escuché decir a Norberto Spolansky en su seminario: "no vayan a pensar que en el derecho penal se termina el derecho".

${ }^{21}$ Puede verse, por ejemplo, y con referencias doctrinales y jurisprudenciales, CN Comercial, Sala F, “Havalon SRL”, Expte. 030080/2013, rta. 19/12/2013. 
Sobre cheques y normas penales en conflicto. Balance de Discusiones 9 (2009)

\section{b) La estructura del delito de libramiento de cheques sin fondos}

En paralelo a lo anterior, existe otra cuestión no analizada en el debate de Discusiones 9 que tiene relevancia para la solución del caso analizado en NP. Me refiero al requisito de "no pago del cheque luego de la intimidación" y su controvertida función (los penalistas suelen hablar de su "naturaleza jurídica"). Esta discusión, que ha ocupado a juristas y jueces por igual, se vincula con la pregunta acerca de cuál es, en definitiva, el delito previsto en el art. 302, inc. 1, del CP. Es indudable que el "no pago" es una condición para que pueda aplicarse la pena, pero es objeto de controversia si tal elemento forma parte del comportamiento prohibido o no. Esto es importante porque de acuerdo con la función que se le atribuya distintas serán las consecuencias que se deriven.

Para los penalistas la clave está en determinar si el "no pago del cheque luego de ser intimado" es un "elemento del tipo objetivo" o una "excusa absolutoria". De manera directamente relacionada con ello se ha entendido que la figura del art. 302, inc. 1, se trata: a) de un "delito plurisubsistente", compuesto de una acción (libramiento del cheque sin fondos) y una omisión (no pago luego de la intimación) [Soler, Fontan Balestra], b) un delito de predominante actividad (el delito consiste en librar un cheque sin fondos) [Borinsky] o c) un delito propio de omisión (el delito consiste en no pagar el cheque rechazado luego de ser intimado) [Bacigalupo] ${ }^{22}$. Lo relevante para el caso analizado en NP es que si se sostiene tesis del delito de pura actividad, lo delictivo únicamente sería el librar el cheque sin fondos y el requisito de "no pago" tan solo constituiría una excusa absolutoria. Por fines distintos a los que hace al comportamiento algo delictivo, el poder legislativo condiciona la punición del hecho a la no concurrencia de un factor (el pago) que, como "puente de plata" o "salvavidas", se le otorga a quien ya cometió un delito.

Ahora, para quien sostenga esta postura, no existiría un conflicto entre deberes jurídico-penales en el caso presentado por Alonso, pues la posibi-

22 Véase, Borinsky, C., Derecho penal del cheque, Buenos Aires, Astrea, 1978, pp. 67-84, con referencias. También, Righi, E. y Juárez, A.L., El régimen penal del cheque, Buenos Aires, Hammurabi, 2014, pp. 99-104. 
lidad de pagar el cheque ante su rechazo es otorgada como una facultad, semejante a una carga procesal, de la que se puede hacer uso o no a fin de evitar la aplicación de una sanción penal. Y una carga no es un comportamiento obligatorio. Dado que es un "beneficio" que otorga la ley, bien podría sostenerse que quien pierde esa posibilidad o no la puede utilizar, por ejemplo, por tener que usar el dinero para otros fines, no tiene derecho a quejarse, del mismo modo que tampoco lo tendría quien pierde la posibilidad de desistir al ser sorprendido durante la ejecución de un delito (al menos para aquellas posturas que consideran al desistimiento de la tentativa una excusa absolutoria) ${ }^{23}$.

Todo lo anterior nos muestra que, en rigor, el caso analizado por Alonso sólo se presenta ante determinada lectura del artículo 302, inciso $1^{\circ}, \mathrm{CP}$ (aquella que ve en él un delito plurisubsistente o de una omisión propia) y del art. 176, inc. 3 (la de quien ve como "indebido" a quien paga un cheque librado previo al concurso o la quiebra). En efecto, los conflictos normativos solo se presentan ante normas, y no entre las formulaciones normativas con las que se las trasmiten o imparten ${ }^{24}$. Claro que Alonso podría responder que aquellos no eran temas que le interesara analizar en $\mathrm{NP}$, pero sin duda, sí serían relevantes para aquel que tenga que opinar ante un caso real (sea un juez, un fiscal, o un defensor).

${ }^{23}$ Se debe reconocer, no obstante, que esto exige apartarse de la definición de Kelsen de "acto ilícito", pues - siguiendo a Nino- en ella no se distingue entre los distintos antecedentes de la sanción que prevé la norma primaria, con lo cual, mecánicamente pasan a formar parte de la norma secundaria. De ese modo, la definición de Kelsen no permite distinguir cuál es el acto ilícito cuando más de un comportamiento del sujeto castigado integra el antecedente de la sanción. Por ejemplo, según la vieja redacción del Código Penal, para sancionar una violación era necesario que el autor no se casara con la víctima. Sin embargo, nadie diría que el no casarse es un acto ilícito. Como señalaba Nino, la dificultad viene dada por la negativa de Kelsen a admitir normas jurídicas directamente prohibitivas diferentes a las que disponen sanciones (Nino, C.S., Introducción al análisis del derecho, Buenos Aires, Astrea, 1998, pp. 177 y 183-184; también, Nino, C. S., Los límites de la responsabilidad penal: Una teoría liberal del delito, Buenos Aires, Astrea, 1980, p. 329, nota 40). Duarte d'Almeida desafía esa interpretación de Kelsen (Duarte d'Almeida, L., op. cit., p. 98, nota 34) y si bien no estoy en condiciones de saldar la disputa hermenéutica, puedo decir que si le asistiera la razón, no cabe duda que Kelsen no fue claro en este punto.

${ }^{24}$ Alchourron, C.E. y Bulygin, E., "La Norma Jurídica”, en Garzón Valdéz, E. y Laporta, F. (eds.), Enciclopedia Iberoamericana de Filosofía. El derecho y la justicia, Madrid, Trotta, 2000, pp. 134-135. 
Sea como fuere, lo dicho hasta aquí lo único que lograría demostrar es que el ejemplo utilizado en NP quizás no era el más indicado para analizar “...las relaciones entre el 'sistema del juez' y el 'sistema del ciudadano' en el específico ámbito del derecho penal, explorando...las peculiares reacciones del sistema normativo del juez (prima facie completo y consistente) ante la existencia de conflictos de deberes jurídico-penales en el sistema del ciudadano" 25 . Sin embargo, eso no quita que efectivamente se trata una problemática digna de atención; muy por el contrario, el conflicto de deberes es un tema sumamente arduo.

\section{La Parte general del derecho penal y los conflictos de deberes jurídicos}

Con solo saber que un comportamiento encuadra en una figura de la parte especial del derecho penal no se puede afirmar que se trate de un delito, pues el hecho pudo haberse cometido bajo un contexto que lo justifique o bien lo exculpe (e incluso cabe la posibilidad que la aplicación de la pena esté condicionado por una condición objetiva de punibilidad o un excusa absolutoria). El texto de Alonso invita a reflexionar muchas cuestiones vinculadas a las causales atipicidad, justificación y exculpación dado que el "conflicto de deberes", tema sobre el que centra su análisis, puede tener consecuencias en esos diversos puntos de análisis dependiendo de las opiniones que se mantengan. En adelante trataré brevemente dos tópicos referidos a tal instituto: el primero, vinculado al principio "deber implica poder" (punto a); el segundo, referido a algunos modos legislativos de dirimir conflictos de deberes (punto b).

\section{a) Conflicto de deberes, "deber implica poder" y condena}

Se presenta un conflicto de deberes cuando ante una situación determinada una persona se enfrenta a dos o más deberes de contenido incompatible. Las normas en los que se fundan esos deberes pueden tener diferente

${ }^{25}$ NP, p. 26. 
origen (normas morales, por ejemplo). El caso analizado por Alonso se refiere a un conflicto de deberes jurídicos fundado en normas extraídas de los artículos 176 y 302 del Código Penal Argentino - por los que lo llama deberes jurídico-penales-y respecto del cual concluye que cualquiera sea el comportamiento que la persona siga estará justificada bajo la causal "cumplimiento de un deber" (art. 34, inc. 4, del CP).

Todo comportamiento típico pero amparado por "el cumplimiento de un deber" tiene en su base un conflicto de deberes: concurre en el caso tanto la prohibición genérica de no incurrir en una conducta típica, como también el mandato opuesto de llevarla a cabo. Para que el conflicto pueda ser resuelto es imprescindible que junto a tales elementos se cuente con un criterio de ordenación, jerarquía o preferencia en virtud de cual preponderará el deber de realizar el comportamiento típico justificado. Es este último factor el que permite decir que el deber que prevalece introduce una excepción al deber que se le opone ${ }^{26}$. Puede ocurrir, incluso, que la elección del criterio de preferencia se deje en manos de la persona que enfrenta el dilema, pues los deberes se estiman de igual peso, y no cometerá un delito siempre y cuando cumpla con alguno ellos.

Los penalistas debaten sobre qué repercusiones deberían tener los supuestos de conflictos de deberes. Existe consenso en que corresponde cumplir con el deber de mayor peso, pero a partir de allí se discute en cómo establecer esa prioridad y qué consecuencias traería aparejada ¿se trata de supuestos de atipicidad o de falta de antijuricidad? Y cuando los deberes tienen igual jerarquía, se agrega la posibilidad de que únicamente se trate de una exclusión de la culpabilidad ${ }^{27}$.

${ }^{26}$ Rodríguez, J.L., "La derrotabilidad de las normas jurídicas" [1997], ahora en Bayón, J. C. y Rodríguez, J. L. (eds.), Relevancia normativa en la justificación de las decisiones judiciales, Bogotá, Universidad Externado, 2003, pp. 86 y 94.

${ }^{27}$ Para un amplio panorama sobre la problemática, con gran cantidad de referencias y propuestas novedosas, véase Coca Vila, I., La colisión de deberes en Derecho penal. Concepto y fundamentos de solución, Barcelona, Atelier, 2016. No puedo aquí siquiera reseñar el texto -que sustancialmente coincide con su tesis doctoral defendida en la Universidad Pompeu Fabra-, en el que somete a la colisión de deberes jurídicos penales a un riguroso análisis, revisando los conceptos involucrados, su estructura normativa, la concreta ubicación sistemática en la teoría del delito y los métodos de solución de conflictos. Se trata, sin duda, de 
Sobre cheques y normas penales en conflicto. Balance de Discusiones 9 (2009)

Puede haber diferentes tipos de configuraciones de conflictos de deberes dependiendo de las variables en juego, sin embargo, hay un factor que se mantiene constante en el trato que debe depararse a quien esté envuelto en uno de ellos, cualquiera sea el camino que haya elegido para sortearlo, que aquí quisiera resaltar. $Y$ es el siguiente: si se va a reprochar/sancionar a esa persona, sólo se lo podrá hacer por un único delito, por más que sean dos, tres o más deberes garantizados con una pena los que entren en escena.

Esto último se puede apreciar fácilmente en los conflictos en los que el cumplimiento de un deber implica necesariamente incumplimiento de otro, y viceversa, ya que es lógicamente imposible cumplir con el contenido de ambos en la misma ocasión. Es el caso analizado en NP: si se paga el cheque se incumple el deber derivado del 176, inc. c; si no se lo hace, el del 302, inc. 1. La sanción, en todo caso, será aplicada a título de uno de esos dos delitos, pero no de ambos. Sin embargo, lo mismo ocurre bajo las configuraciones en las cuales, si bien el sujeto no puede cumplir con los dos deberes de modo acumulativo, sí podría hacerlo de manera alternativa. En tales casos está abierta una tercera opción: que el obligado desatienda los dos deberes. Esta posibilidad está presente en el clásico ejemplo del padre que en un naufragio tiene que optar entre salvar a un hijo o a otro porque le es físicamente imposible rescatarlos a ambos (Alonso alude al ejemplo en p. 56) ${ }^{28}$. El padre está frente a un deber alternativo ("debes salvar a una $o$ al

una obra imprescindible y actual para quien desee tener una completa y profunda mirada de un instituto que casi no ha recibido atención entre los penalistas de habla hispana.

${ }^{28}$ El padre debe salvar a sus hijos, pero bajo esa limitación fáctica (físicamente no puede salvar a los dos) cada una de las acciones necesarias para hacerlo pasan a estar mandada y prohibida a la vez: el padre está obligado a salvar a su hijo A, pero también está prohibido que lo haga (porque debe salvar a su hijo B) y está obligado a salvar a su hijo B, pero simultáneamente lo tiene prohibido (porque debe salvar a su hijo A). En casos de esta configuración la colisión de deberes no tiene origen en un conflicto normativo dado a nivel de las normas generales del sistema normativo con el que se está trabajando (la acción de "salvar a un hijo" no está mandada y prohibida al mismo tiempo), sino que son las circunstancias fácticas presentes en el caso las que hacen imposible cumplir con los dos mandatos que nacen de la norma general aplicable. Se trata de un conflicto de instanciación, según la terminología utilizada por Jorge L. Rodríguez (Rodríguez, J.L., Razonamiento y Decisión Judicial, La justificación de las decisiones judiciales en las democracias constitucionales, Buenos Aires, Ministerio de Justicia y Derechos Humanos de la Nación, 2017, pp. 157-163) En esta clase de conflictos son las normas individuales derivadas de una o más normas 
otro") pues no está en condiciones de salvar a los dos hijos, pero también es cierto que podría optar por no salvar a ninguno.

Como se dijo, cualquiera sea la configuración del conflicto de deberes penales, únicamente se podrá condenar por el incumplimiento de uno de los mandatos. Y si el padre náufrago, en lugar de ponerse a nadar, se cruza de brazos y no hace nada por cualquiera de sus hijos, solo se lo podría condenar (reprochar y/o condenar) por un homicidio, pero no por dos. No cabe duda que son dos los muertos ( $\mathrm{y}$ al ejemplo se le podrían agregar más hijos ahogándose), como así también que el padre no hizo nada por ninguno ellos, sin embargo, eso no quita que, de haber actuado, tan solo podría haber salvado a uno. Esto tiene que ver con que un prerrequisito de todo mandato es el llamado principio voluntarista de "deber implica poder"29. El padre no está en condiciones de salvar a ambos (no puede hacerlo) y precisamente eso es lo que lo distingue de otro padre que deja ahogar a uno de sus hijos y a la semana siguiente, enfrentado a la misma situación, deja morir al otro. En el último caso sí podrían imputarse las dos muertes, pero si "deber implica poder”, en el clásico ejemplo del naufragio solo una de ellas podría atribuírsele a la decisión del padre de no actuar. Y no podríamos imputárselas por el mismo motivo que no lo haríamos - siquiera por una de esas muertes-si directamente el padre no supiera nadar. Por lo tanto, manteniéndose en resto

generales las que colisionan al no resultar físicamente posible cumplir ambas, mientras que las normas generales de las que se derivan, en sí mismas, no entran en conflicto con otras normas generales del sistema. Para graficarlo Rodríguez utiliza el ejemplo de la norma que establece la obligación de pagar las deudas a su vencimiento y la situación de un sujeto que contrae dos deudas pero que el día de pago solo cuenta con dinero para cancelar una. Dicho sea de paso: a la luz de ese ejemplo puede apreciarse que, en rigor, todo el procedimiento de concursos y quiebras (ley 24.522) es una compleja regulación omnicomprensiva de casos de conflictos de instanciación (el acreedor no puede honrar todas sus deudas) bajo criterios que fueron elegidos legislador para dirimirlos y gestionarlos (cada acreedor sacrificará algo ya sea que se traduzca en una quita, espera o remisión, pero potencialmente todos podrán obtener algo de la masa de activos del deudor) aunque podrían haberse elegido otros (por ejemplo, que cada acreedor cobre lo que pueda, lo que implica aceptar como una posibilidad el que alguno logre cobrar el $100 \%$ pero otros nada). No existe un único método distributivo y la elección que se haga arrojará diferentes resultados (Véase, García G.F., "Cómo resolver un conflicto distributivo", Isegoría, 54, 2016, pp. 276-288).

${ }^{29}$ El principio es generalmente atribuido a Kant. Véase Stern, R., "Does 'Ought' Imply 'Can'? And Did Kant Think It Does?”, Utilitas, 16, 1, 2004, pp. 42-61. En ámbitos jurídicos se alude al principio con las formulas "ultra posse nemo obligatur" o "impossibilium nulla obligatio". 
Sobre cheques y normas penales en conflicto. Balance de Discusiones 9 (2009)

de las condiciones iguales, los padres de los ejemplos nunca deberían recibir la misma condena (reproche y/o sanción) ${ }^{30}$.

Al margen de ello, el principio voluntarista también impone la introducción de una aclaración terminológica. Usualmente hablamos de "conflicto de deberes" (y aquí se continuará con ese hábito), pero si sólo uno de ellos puede ser cumplido y a la vez aceptamos que "deber implica poder", entonces únicamente constituirá un deber en sentido estricto aquel que prepondere, ya sea que esa decisión la haya tomado el legislador o se la hayan conferido a la persona envuelta en el conflicto, ante la equivalencia de peso de los mandatos en pugna.

\section{b) Algunos modos legislativos de dirimir conflictos de deberes}

Cuando se trata de un conflicto de deberes, es necesario un criterio que le permita al juez y al ciudadano definir cuál debe ser aplicado. A tales fines se acostumbra utilizar los criterios de lex superior (ley superior prevalece sobre la ley inferior), lex specialis (ley especial prevalece sobre la ley general) y lex posterior (ley posterior prevalece sobre la ley anterior) ${ }^{31}$. El caso estudiado en NP, como muchos otros analizados bajo la categoría de "conflicto de deberes", se refiere a dos normas dictadas por la misma

${ }^{30}$ Puede que intuitivamente el padre del naufragio que no salva a ninguno de sus hijos nos genere más indignación que otro que no salva a un hijo pudiéndolo hacerlo (lo último lo consideramos malo, pero lo primero nos parece aún peor). Sin embargo, quizá eso se deba a que en nuestro reproche estemos incluyendo un juicio sobre la valoración moral de su persona, es decir, que lo estemos juzgado desde el punto de vista de una moral autorreferente (Véase Nino, C.S., Introducción a la filosofía de la acción humana, Buenos Aires, Eudeba, 1987, pp. 111-112, donde distingue una valoración moral intersubjetiva y una autorreferente). O bien porque no comprendemos cómo alguien puede ser indiferente ante tanto dolor o bien porque nos damos cuenta de que en verdad el padre no sentía nada por sus hijos. Pero no todo es tan contundente: ¿qué diríamos ante el padre, a quien la vida trágicamente lo ha enfrentado al "dilema de Sophie", si nos dijera que lo hizo porque no podría vivir con semejante culpa?

31 Acerca de que los criterios de lex superior, lex specialis y lex posterior, utilizados resolver conflictos normativos, no son de aplicación mecánica ni tienen un carácter lógico, como así tampoco permiten resolver todos los conflictos posibles (ej. ¿̇la ley posterior general deroga la anterior especial?), véase Ross, A., Sobre el derecho y la justicia, Buenos Aires, Eudeba, 1997, pp. 164-170., y Nino, C. S., Introducción al análisis del derecho, op. cit., pp. 275-276. 
autoridad y en el mismo momento, por lo que los criterios de lex superior y lex posterior no pueden operar. Resta analizar si el criterio de especialidad podría brindarnos la solución.

En general no nos resulta difícil establecer qué norma desplaza a otra. El ejemplo del allanamiento y el delito de violación de domicilio son claros en ese sentido. La regla que le brinda autoridad al juez para disponer allanamientos y la que lo obliga disponerlo con el fin de obtener cosas relacionadas con el delito, preponderan o exceptúan la que prohíbe introducirse en un domicilio ajeno ${ }^{32}$. A su vez, nadie tiene en principio un derecho a introducirse a un domicilio de otra persona, pero si se trata de un testigo de actuación que ha sido convocado por un agente de policía que recibió la orden de allanamiento dictada por el juez, entonces esas personas están obligadas a entrar al domicilio. Lo propio ocurre con el delito de hurto y el secuestro de alguna cosa total o parcialmente ajena en el marco del allanamiento, o con el delito de privación de libertad y la detención llevada a cabo por un funcionario ante la comisión de un delito flagrante.

En casos como esos la respuesta se tan clara que muchas veces siquiera reparamos en la existencia de un conflicto de normas ni en el criterio que se ha utilizado para privilegiar un deber sobre otro. Esto está emparentado con las alusiones que las formulaciones de los delitos suelen contener. En el Código Penal Argentino, por ejemplo, el delito de hurto está previsto para el que se "apoderare ilegítimamente" (art. 162), la privación de libertad será delictiva en tanto se lo haga "ilegalmente" (art. 141), y la violación de domicilio será delito para el funcionario que allane "sin las formalidades prescriptas por ley o fuera de los casos que ella determina" (art. 151). En esos supuestos, en lugar de conflictos de normas solucionados por la autoridad normativa, parece más natural hablar del proceso de identificación de la normas a partir de las formulaciones normativas, lo que se hace tomando en cuenta las convenciones semánticas y las prácticas interpretativas de los operadores jurídicos, que incluyen las reglas de preferencia o prioridad ${ }^{33}$.

${ }^{32}$ El juez está amparado por actuar "en ejercicio de un cargo". Esta causal constituye una variante de actuar en "cumplimiento de un deber". Lo que diferencia ambos casos es que en el de "ejercicio de un cargo" concurren normas de competencia además de las de obligación.

${ }^{33}$ Rodríguez, J. L., op. cit., pp. 97-99 y "Derrotabilidad e indetermianción del derecho. Respuesta a Juan Carlos Bayón” [2001], pp. 218-219; así como también, Bayón, J. C., “Derro- 
Sobre cheques y normas penales en conflicto. Balance de Discusiones 9 (2009)

A través de tales ejemplos puede contemplarse la manera en la que el poder legislativo ya ponderó todos los intereses en juego y no sólo habilitó a introducir excepciones a la prohibición de cometer ciertos hechos que de lo contrario serían antijurídicos (violación de domicilio, hurto, privación de la libertad), sino que incluso los tornó obligatorios para algunos funcionarios. En rigor, la pugna entre deberes no es más que una manifestación de un fenómeno más general que se vincula con la existencia de diversos intereses, objetivos, valores o mandatos que confluyen ante una misma situación y la imposibilidad de satisfacerlos a todos por igual. Y es algo bastante más extendido de lo que a primera vista parece, solo que suele pasar desapercibido detrás de una difusa distinción entre excepciones que forman parte del contenido de una misma norma y el conflictos entre normas diferentes cuyo contenido no resulta modificado, o incluso se cuelan inadvertidamente en discusiones sobre el contenido o alcance de derechos (por ej. que una legislación imponga el deber de guardar secreto profesional a los médicos de hospitales estatales a pesar de que se tratan de funcionarios públicos, cargo que importa la obligación de denunciar los delitos de los que toman conocimiento en el ejercicio de la profesión ¿es la regulación de un conflicto de deberes o la delimitación de los derechos de privacidad y la salud de los pacientes? ${ }^{34}$ ).

El ejemplo analizado en NP no es uno de aquellos casos fáciles. Ya vimos lo complejo que resulta establecer el alcance de la "ventaja indebida" mencionada en el art. 176, inc. 3, del CP (punto 3). Pero al margen de eso, el supuesto tampoco podría ser solucionado apelando al criterio de especialidad (lex specialis). Ocurre que ambas normas pueden reclamar para sí el mismo grado de generalidad: la prohibición de pagar un cheque intimado luego de iniciado el concurso o decretada la quiebra es un caso especial que exceptúa la obligación genérica de pagarlos que es respalda

tabilidad, Indeterminación del derecho y positivismo jurídico [1997], pp. 184-185, todos en Bayón, J.C. y Rodríguez, J. L. (eds.), op. cit.

${ }^{34}$ En última instancia esto remite a la discusión sobre si es posible hablar de "conflicto de derechos" o si una vez que son correctamente delimitados ellos "viven en perfecta armonía". Véase un análisis sobre la cuestión, con referencias, en Martínez Zorrilla, D., Conflictos constitucionales, ponderación e indeterminación normativa, Madrid, Marcial Pons, 2007, pp. 183-202. 
por el art. 302, inc. 1, CP, pero del mismo modo podría decirse que la regla general del art. 176, inc. 3 , del CP de no brindar ventajas a los acreedores es exceptuada cuando se trate de la intimación al pago de un cheque, que pasa a ser un caso especial ${ }^{35}$.

Quizá por eso la mayoría de los intervinientes en Discusiones 9 optaron por intentar dirimir el conflicto por otro criterio y ese fue el de las escalas penales previstas para cada delito. Ello, en el entendimiento de que se trataría un indicador de peso (aunque no determinante) para desentrañar el valor que el legislador le otorga a los deberes en pugna. La idea es que la consecuencia seguida de la infracción de la norma es lo que nos brindará la pauta de su relevancia, de modo que a mayor pena (y dando por presupuestos ciertos factores, por ej. que ambas figuras atrapan la misma modalidad e intensidad de ataque) más importante será el deber para la autoridad legislativa. Sin embargo, no siempre es sencillo hacer esas comparaciones y el debate generado por NP da cuenta de eso. Mientras que a Alonso le parece difícil sostener que la escala del art. 176 sea más grave que la del art. 302, Peralta y Ortiz Urbina opinan lo contrario, por lo que le otorgan mayor peso al deber de no pagar el cheque que al de hacerlo ${ }^{36}$. En la intersección de ambas posturas se encuentran los casos cuya pena en concreto debería ser fijada en la sección de la escala que las figuras comparten (a saber, 2 a 4 años de prisión e inhabilitación especial de 3 a 5 años). El análisis de qué tratamiento debiera darse a esos supuestos es un tema interesante que merece ser profundizado, pues nos invita a preguntarnos si para comparar el peso de los deberes en conflicto, más que contrastar la escala prevista en abstracto para cada figura delictiva, no debiéramos prestar atención a la pena que en concreto habría que atribuir a cada hecho. Un interrogante generado gracias al intercambio entre Alonso y Peralta ${ }^{37}$.

35 Alejandra Verde no está de acuerdo con esto y considera que “...el deber específico del declarado en quiebra de no pagar un cheque prevalece sobre el deber general de no violar la fe pública" (Verde, A., "Fundamento y límites de la impunidad por colisión de deberes en derecho penal", Discusiones, 9, 2009, p. 125).

36 Ortiz de Urbina G.I., "Martillos y Clavos: una respuesta a 'Normas penales y conflicto de deberes', de Juan Pablo Alonso", Discusiones, 9, 2009, pp. 78-80. Peralta, J.M., op. cit., pp. 133-140.

${ }^{37}$ Peralta, J.M., op. cit., pp. 136-139 y Alonso, J.P., “Respuesta a las críticas”, op. cit., p. 176. 
Sobre cheques y normas penales en conflicto. Balance de Discusiones 9 (2009)

Al margen de todo ello, el recurso de las escalas penales es una opción a la que se echa mano ante falta de aclaraciones expresas por parte del legislador sobre cómo proceder frente a estas situaciones ${ }^{38}$. Hasta donde alcanzo a ver, cuando la autoridad legislativa tiene en claro cómo dirimir un conflicto, la remisión a esa solución suele aparecer consignada en la formulación de la figura delictiva (como vimos que sucede en los arts. 141, 151 y 162 del CP).

Sin embargo, cuando ello no ocurre, la técnica legislativa más empleada consiste en utilizar fórmulas generales como las que conocemos sobre la legítima defensa, el estado de necesidad, el cumplimiento de un deber, etc.. Por cierto, ello no deja de ser prudente, pues es una característica de la condición humana no poder prever toda posible combinación de factores que puede traer un caso, ni su relevancia (la relativa ignorancia de los hechos e indeterminación de fines de la que hablaba Hart $)^{39}$.

\section{Algunas cuestiones vinculadas a la Teoría general del derecho}

Recordemos que Alonso se pregunta sobre un supuesto en el que los sistemas del juez y del ciudadano presentan una anomalía: mientras que para el juez el sistema es completo y consistente, para el ciudadano contiene una contradicción que lo sumerge en un conflicto. Al juez se le dice: si el ciudadano paga el cheque, corresponde condenarlo bajo el art. $176 \mathrm{del}$ CP; si no lo paga, la condena será por el art. 302 del CP. Al ciudadano, en

${ }^{38}$ El poder legislativo podría dar directivas sobre el punto. Salvando las distancias, eso es lo que ocurre con códigos de procedimientos que fijan criterios acerca de cómo establecer la gravedad de los hechos investigados en diferentes expedientes, para establecer su acumulación y el tribunal que deberá intervenir. Por ejemplo, el art. 34 CPPN establece: "Para determinar la competencia se tendrá en cuenta la pena establecida por la ley para el delito consumado y las circunstancias agravantes de calificación, no así la acumulación de penas por concurso de delitos de la misma competencia. Cuando la ley reprima el delito con varias clases de pena, se tendrá en cuenta la cualitativamente más grave."

39 Véase Moreso, J.J., "Principio de legalidad y causas de justificación (Sobre el alcance de la taxatividad)", Doxa, 24, 2001, pp. 525-545, con referencias. 
cambio, se le informa: está obligado a pagar el cheque (302 CP) y también a no pagarlo $(176 \mathrm{CP})^{40}$.

Si bien puede parecer que NP analizará el problema a un nivel general, con una temática de Teoría del derecho, sin aludir a un ordenamiento jurídico concreto ( $¿$ debe "reaccionar" el sistema del juez ante un sistema como el que enfrenta el ciudadano?), luego queda claro que Alonso se refiere al derecho penal argentino, de donde toma una específica regulación para tratar la cuestión y darle una respuesta: el art. 34 , inc. $4, \mathrm{CP}^{41}$. Sin embargo, no por eso deja de ser interesante pensar el problema teórico con abstracción de la legislación penal argentina ¿Cómo debería ser tratado un caso como el estudiado en NP frente a un sistema que careciera de una disposición legal expresa como la que finalmente utiliza Alonso? En lo que sigue trataré únicamente la alternativa en la cual el sistema del juez es indiferente al conflicto presente en el sistema del ciudadano - por lo cual éste deberá

40 Alonso afirma que NP tratará una alternativa patología distinta a la analizada por Alchourrón y Bulygin en la obra que cita (p. 26 -alude a las lagunas normativas en el sistema del ciudadano-). Sin embargo eso puede ser relativizado, pues tampoco en el caso de conflictos de normas (no resueltos) el sistema del ciudadano contiene una solución para el caso (conf. Bulygin, E., "Los jueces ¿crean derecho?", Isonomía, 18, 2003, p. 25). Al margen de ello, Alonso utiliza una noción de "sistema del juez" y "sistema del ciudadano" diferente a la de estos autores cuando afirma que respecto a los arts. 176, inc. 3, y 302, inc. 1, que el sistema del juez es completo y consistente mientras que en el del ciudadano se registra un conflicto de deberes jurídico-penales (pp. 31 y 41). En el análisis de Alchourrón y Bulygin "La obligación de fundar en derecho una sentencia normativa es la exigencia de usar - para la fundamentación de ella- el sistema del súbdito...En este sentido el sistema del juez es secundario con respecto al sistema del súbito, ya que presupone la existencia. Precisamente en virtud de que los jueces están obligados a resolver los conflictos de intereses fundando sus decisiones en el sistema [del súbdito]..., las normas del sistema del juez se refieren - directa o indirectamente- a otras normas y son, por consiguiente, normas de segundo nivel” (p. 213). De ahí que “...si el sistema... [del súbdito] nada dice acerca del status deóntico de la conducta del demandado, el juez no puede cumplir con la obligación de fundar su decisión en ese sistema, cualquiera que sea la decisión que adopte..." (pp. 217-218. Las citas corresponden a Alchourrón, C. y Bulygin, E., Introducción a la metodología de las ciencias jurídicas y sociales, $4^{\mathrm{a}}$ reimpresión, Buenos Aires, Astrea, 2002, traducción del original en inglés Normative Systems, Wien, 1971 a cargo de los autores).

${ }^{41}$ En la nota al pie 20 de NP (p. 48) y de modo terminante en Alonso, J. P., "Respuesta a las críticas", op. cit., pp. 172 y 173. 
Sobre cheques y normas penales en conflicto. Balance de Discusiones 9 (2009)

ser condenado pague o no pague el cheque $\mathrm{e}^{42}-\mathrm{y}$ asumiré también que el sujeto no es responsable de encontrarse en la situación conflictiva ${ }^{43}$. El análisis puede ser dividido según la búsqueda de la respuesta pueda ser obtenida desde el interior ordenamiento jurídico (punto a) o mirada con una perspectiva externa (punto b).

\section{a) La opción por sancionar vista desde el interior del ordenamiento jurídico}

Dado que por hipótesis el sistema carece de una norma legal expresa que trate el punto, el primer tipo de análisis podría ser hecho en función del resto de las normas de igual jerarquía del ordenamiento jurídico con el fin de determinar si por razones de coherencia y respeto a la igualdad o en virtud de algún principio implícito, el juez debiera reparar en el conflicto en que se lo sumerge al ciudadano. Alonso ha escrito valiosos trabajos en sobre todo ello ${ }^{44}$. En ese punto seguramente tendrán un rol protagónico las disposiciones vinculadas al estado de necesidad justificante y exculpante. De hecho, son varios los penalistas que consideran que la mayoría de los supuestos de "conflictos de deberes" no debieran tener una regulación distinta a la del estado de necesidad ${ }^{45}$.

Ahora, si lo anterior no se lo considerase viable, la cuestión tiene que ser mirada aún desde el interior del propio ordenamiento jurídico, pero a partir del prisma de una lex superior. Desde ese plano, existen argumentos

${ }^{42}$ Respecto a los sistemas del juez no indiferentes al sistema del ciudadano, pero en los cuales el conflicto se presenta entre normas interdependientes respecto de las que no es posible establecer qué deber prepondera sobre cuál, puede verse el interesante análisis que hace Peralta respecto al principio de legalidad penal (Peralta, J.M., op. cit., pp. 144-148). Acerca de cómo justificar la preferencia de un deber frente otro, en el marco de un ordenamiento que reconoce a cada ciudadano una esfera de libertad propia, puede verse Coca Vila, I., op. cit.

${ }^{43}$ Peralta explora esta variable en Peralta, J.M., op. cit., pp. 148-159 ("sanción bajo las dos alternativas: la responsabilidad según las reglas de la actio illicita in causa”).

${ }^{44}$ Alonso, J.P., Interpretación de las normas y derecho penal, Buenos Aires, Del Puerto, 2006; también, Alonso, J.P., “Principios implícitos y fuentes sociales del derecho”, Doxa, 2018 (en prensa).

45 Véase, Roxin, op. cit., $\$ \$ 16$ y 100-110, pp. 724-731. También, Coca Vila, I., op. cit., pp. 60-82, con referencias. 
constitucionales a considerar para contestar el interrogante de si el sistema del juez debe reparar en el conflicto en el que está situado el ciudadano en el caso analizado en NP; de hecho, Alonso da razones de esta clase cuando descarta como viable la opción de condenar bajo cualquier supuesto. No de otro tipo son sus argumentos sobre la falta de dominabilidad, la afectación del principio de legalidad o su afirmación de que el derecho penal evaluar conductas humanas y que por ello debe ponderar razones, circunstancias y condicionamientos que llevaron al agente a obrar como lo hizo.

Apelar a argumentos constitucionales no es ajeno a la historia del derecho penal argentino. Por ejemplo, frente a un código penal como el que actualmente rige en la Argentina, que no prevé expresamente la operatividad del error de prohibición o de derecho, fueron argumentos constitucionales los que terminaron por imponer esa postura en la jurisprudencia. Así, frente al brocardo error juris nocet y el art. 20 del Código Civil que establecía: "La ignorancia de las leyes no sirve de excusa...", autores como Bacigalupo, Spolansky y Sancinetti argumentaban que la virtualidad de esa clase de error debía ser aceptada por imperio del principio constitucional de culpabilidad ${ }^{46}$.

$\mathrm{Al}$ igual que aquella discusión, también aquí el principio de culpabilidad invalidaría la imposición de un castigo bajo cualquiera de los supuestos en un caso como el analizado en $\mathrm{NP}^{47}$. Este principio requiere que la realización de la acción prohibida sea evitable, de modo que si se lleva a cabo, la comisión del hecho sea atribuible a una falta de motivación dominante de comportarse de acuerdo a lo que exige el derecho por parte de la

${ }^{46}$ Véase, por todos, Sancinetti, M. A., Sistema de la teoría del error en el Código Penal argentino, Buenos Aires, Hammurabi, 1990, pp. 33-34 y 248, con referencias.

${ }^{47}$ El argumento de Alonso sobre la dominabilidad o su postulación acerca de que el derecho penal evalúa comportamientos deben recalar en el principio de culpabilidad si no quieren quedar en el plano de una petición de principio. Por otro lado, el argumento de la afectación al principio de legalidad no tiene el mismo peso para dirimir la cuestión, pues en todo caso, ataca al modo en que actualmente estaría prevista la sanción (por combinación de dos figuras delictivas y la concurrencia de determinadas circunstancias fácticas -pp. 46-47-), pero no a lo que se está sancionando y es precisamente esto último lo que atenta contra el principio de culpabilidad. 
Sobre cheques y normas penales en conflicto. Balance de Discusiones 9 (2009)

persona $^{48}$. En cambio, si el sujeto será castigado haga lo que haga, ya no le será posible comportarse conforme a derecho. Como decía Nino, penar tanto una acción como su omisión (matar o no matar, por ejemplo), no es substancialmente diferente de penar a alguien por algo que no pudo controlar (como el color de su piel) y:

...[s]i la voluntariedad de la acción se excluye cuando ésta es empíricamente necesaria, con más razón deberá excluírsela cuando la acción sea lógicamente necesaria ${ }^{49}$.

\section{b) La opción por sancionar vista desde el exterior del ordenamiento jurídico}

Resta ahora analizar el desacople entre el sistema de juez y el del ciudadano por fuera de un ordenamiento jurídico. Asumamos que ese desacople existe y que el sistema no contiene ni expresa ni implícitamente una previsión a nivel legal o constitucional a la que acudir para resolver la situación (no rige, por ejemplo, el principio de culpabilidad). Bajo esas condiciones el sistema del juez indica que se castigará de todos modos y lo único que podría varias sería el título de la condena, es decir, aplicará el art. 176 o el art. 302 del CP, dependiendo que se pague o no el cheque.

Es habitual escuchar que los sistemas normativos, los conjuntos de normas, tienen dos funciones prácticas principales: evaluar las acciones humanas y guiar las conductas de las personas. Un sistema como el que ahora estamos analizando (que prevé la condena bajo cualquiera de las alternativas en las que se encuentra el sujeto) permitirá evaluar conductas humanas (al menos si por "evaluación" se entiende la provisión de un patrón o medida para que el juez determine qué consecuencia normativa el ordenamiento jurídico imputa a un comportamiento: en el caso se aplicará el art. 176 o el 302 del CP). Pero lo que sin duda no alcanzará

48 Jakobs, G., "El principio de culpabilidad", en Estudios de Derecho Penal, Madrid, Cívitas, 1997, pp. 366 y ss. Véase también, Córdoba, F.J., "De nuevo sobre la relación entre prevención general positiva y culpabilidad”, Letra Penal, Año II, 4, 2017, pp. 43 y ss.

49 Nino, C. S., Los límites de la responsabilidad penal..., op. cit., pp. 243-244. 
un ordenamiento con ese tipo de inconsistencias es el objetivo de guiar el comportamiento de los ciudadanos, pues de manera contradictoria se le estará diciendo a quien se encuentre en esa situación que debe pagar el cheque pero que también debe no hacerlo ${ }^{50}$.

Para von Wright un legislador que dicta normas con contenido mutuamente contradictorios actúa irracionalmente dado que desea algo lógicamente imposible ${ }^{51}$. Se puede ordenar algo y también su contradictorio, pero no se puede esperar que ambos mandatos sean cumplidos, pues es imposible hacerlo. Sin embargo, ese análisis todavía puede hacerse desde otro plano. Por ejemplo, Fuller se preguntaba:

... [i] hay alguna violación a la lógica en obligar a una persona a hacer algo y luego sancionarlo por ello? Seguramente diremos que esa forma de proceder no tiene sentido, pero al hacer este juicio estamos tácitamente asumiendo el objetivo de darle una dirección con sentido al esfuerzo humano. Difícilmente podrá esperarse de un hombre que habitualmente se lo sanciona por hacer lo que le fue ordenado, que responda de modo apropiado a las órdenes que se le brinden en el futuro. Si nuestra forma de tratarlo es parte de un intento de construir un sistema de reglas para gobernar su conducta, entonces fracasaremos en el intento. Por otro lado, si nuestro objetivo es causarle un colapso nervioso, seguramente lo lograremos. Pero en ninguno de los casos habremos infringido la lógica ${ }^{52}$.

Permítanme dejar de lado la última afirmación sobre la lógica. Las contradicciones normativas o antinomias disparan toda una serie de discusiones conceptuales acerca de si pueden existir en sentido estricto normas contradictorias o si pueden formar parte de un sistema normativo, y no

${ }^{50}$ Alchourrón, C.E., "Conflictos de normas y revisión de sistemas normativos", en Alchourón, C. E. y Bulygin, E., Análisis Lógico y Derecho, Madrid, Centro de Estudios Constitucionales, 1991, pp. 291 y 301 . También, Bulygin, E., "Comments on Larry Alexander 'Legal Positivism and Originalist Interpretation"', Revista Argentina de Teoría Jurídica, 16, Agosto, 2015, p. 4.

${ }^{51}$ von Wright, G. H., “Ser y deber ser", en Aarnio, A., Garzón Valdés, E., Uusitalo, J. (eds.), La normatividad del derecho, Barcelona, Gedisa, 1997, p. 98.

52 Fuller, L. L., The Morality of Law, 2a edition, Yale University, 1969, p. 66 (traducción del autor). 
Sobre cheques y normas penales en conflicto. Balance de Discusiones 9 (2009)

viene al caso discutir todo ello aquís3. Lo que quisiera resaltar es el diferente sentido con que se juzga irracional o racional el dictado de normas contradictorias. En rigor, todo depende de qué es lo que se está intentando lograr. Es cierto que si lo que pretende la autoridad es guiar el comportamiento, no lo logrará dictando normas contradictorias (von Wright), pero si lo que busca es imponer una pena al individuo a toda costa, entonces el método se presenta como adecuado al fin (Fuller) ${ }^{54}$. En ese caso el sistema le proveerá al juez los criterios sobre qué sanción imponer y resultará por entero irrelevante analizar qué opciones tenía el sujeto al que se le aplica. Sin embargo, como contrapartida puede decirse que el individuo que esté sometido a funcionarios regidos por un conjunto de normas de esa clase, se verá sujeto a la manipulación y al desquicio. Respecto a él no regirá el principio "deber implica poder" y difícilmente lo podríamos llamar "ciudadano", desde que no se estará garantizada ni su autonomía, ni su dignidad.

En un sistema de normas como el imaginado, al juez se le ordena condenar por el delito del 302 si el sujeto no paga el cheque, y por art. 176, si lo hace. Ante esta situación algunos podrán decir que se trata un caso jurídicamente fácil, pues el ordenamiento jurídico permite identificar y aplicar el derecho sin recurrir a consideraciones valorativas de ninguna clase (sin que ello los obligue necesariamente a negar que se trata de un caso moralmente difícil y que según, la postura, incluso pudiera repercutir en la cuestión de si la norma jurídica deba ser aplicada). Otros, que normas que impongan sanciones penales que no pueden ser evitadas no podría ser llamadas "derecho" porque no lo son las leyes (o los ordenamientos, si la situación no es un ejemplo aislado) que prevén regulaciones injustas o que aquello será así si la injusticia alcanza un grado extremo. Como vemos,

${ }^{53}$ Alchourrón, C.E. y Bulygin, E., "Von Wright y la filosofía del derecho", en Alchourrón, C. E. y Bulygin, E., op. cit., pp. 79-84. Moreso, J. J., "Von Wright sobre 'ad impossibilia nemo tenetur"', Doxa, 39, 2016, pp. 85-95.

${ }^{54}$ Para quien, gracias a una barrera definicional, no considere que esa medida constituya una "pena" (dado que por definición exige, por ejemplo, que sea aplicada a quien pudo evitar ser sancionado), puede buscar el nombre que estime conveniente para llamar a la imposición de dolor y/o privación de derechos a las que se verá sujeto el individuo. Sobre la definición de pena y las barreras definicionales, Hart, H.L.A., "Prolegomenon to the Principles of Punishment", en Punishment and Responsibility. Essays in the Philosophy of Law, Oxford, Oxford University Press, 2008, p. 5. 
Santiago Roldán

la discusión da paso ahora a los debates sobre las teorías positivistas y no positivistas del derecho, con todas sus variantes.

\section{Conclusión}

A lo largo del texto he abordado un puñado de temas vinculados con el número 9 de la revista Discusiones. Por cierto, no son los únicos y bien podrían elegirse otros como objeto de reflexión. Sin embargo, sean cuales fueren, pienso que el texto de Juan Pablo Alonso y su análisis son una buena prueba de que, entre los argumentos que alimentan las discusiones jurídicas que se dirimen en los tribunales, se escurren silenciosamente temas de mayor abstracción que incluso llegan a la Teoría general del derecho. ¡Y ello ocurre aunque la controversia gire alrededor de algo tan técnico como un cheque! Mostrar la fecundidad de esa interrelación, pienso, es el mejor balance que se puede hacer de aquel número de la revista Discusiones y el debate que en él se generó.

\section{Bibliografía}

Alcácer Guirao, R., "La protección del futuro y los daños cumulativos", RECPC, 04-08, 2002, disponible en http://criminet.ugr.es/recpc/ recpc_04-08.pdf.

Alchourrón, C.E., "Conflictos de normas y revisión de sistemas normativos", en Alchourrón, C. E. y Bulygin, E., Análisis Lógico y Derecho, Madrid, Centro de Estudios Constitucionales, 1991, pp. 292-302.

Alchourrón, C.E. y Bulygin, E., "Von Wright y la filosofía del derecho", en Alchourrón, C. E. y Bulygin, E., Análisis Lógico y Derecho, Centro de Estudios Constitucionales, Madrid, 1991, pp. 69-102.

Alchourron, C.E. y Bulygin, E., "La Norma Jurídica”, en Garzón Valdéz, E. y Laporta, F. (eds.), Enciclopedia Iberoamericana de Filosofía. El derecho y la justicia, Madrid, Trotta, 2000, pp. 133-148.

Alchourron, C.E. y Bulygin, E., Introducción a la metodología de las ciencias jurídicas y sociales, Buenos Aires, Astrea, 2002. 
Sobre cheques y normas penales en conflicto. Balance de Discusiones 9 (2009)

Alonso, J.P., Interpretación de las normas y derecho penal, Buenos Aires, Del Puerto, 2006.

Alonso, J. P., “Normas penales y conflicto de deberes”, Discusiones, 9, 2009, pp. 21-60.

Alonso, J.P., "Respuesta a las críticas”, Discusiones, 9, 2009, pp. 161-180.

Alonso, J.P., "Principios implícitos y fuentes sociales del derecho", Doxa, 2018 (en prensa).

Bayón, J.C., "Derrotabilidad, Indeterminación del derecho y positivismo jurídico”, en Bayón, J.C. y Rodríguez, J. L. (eds.), Relevancia normativa en la justificación de las decisiones judiciales, Bogotá, Universidad Externado de Colombia, 2003, pp. 157-208.

Bergel, S.D., "Convocatoria de acreedores y delito de cheques sin provisión de fondos", $E D, 33,1970$, pp. 803-811.

Borinsky, C., Derecho penal del cheque, Buenos Aires, Astrea, 1978.

Bulygin, E., "Los jueces ¿crean derecho?”, Isonomía, 18, 2003, pp. 7-25.

Bulygin, E., “Comments on Larry Alexander 'Legal Positivism and Originalist Interpretation", Revista Argentina de Teoría Jurídica, 16, Agosto, 2015, disponible en https://www.utdt.edu/ver_contenido. php?id_contenido=111698id_item_menu=5858.

Duarte d'Almeida, L., "Deberes Jurídicos, Teoría del Derecho y Dogmática Penal", Discusiones, 9, 2009, pp. 85-110.

Coca Vila, I., La colisión de deberes en Derecho penal. Concepto y fundamentos de solución, Barcelona, Atelier, 2016.

Córdoba, F.J., "De nuevo sobre la relación entre prevención general positiva y culpabilidad", Letra Penal, Año II, 4, 2017, pp. 43-64.

Fontanarrosa, R.O., Régimen Jurídico del Cheque, Buenos Aires, Zavalía, 1986. García G.F., "Cómo resolver un conflicto distributivo”, Isegoría, 54, 2016, pp. 275-288.

Hart, H.L.A., "Prolegomenon to the Principles of Punishment", en Punishment and Responsibility. Essays in the Philosophy of Law, Oxford, Oxford University Press, 2008, p. 1-27.

Jakobs, G., "El principio de culpabilidad”, en Estudios de Derecho Penal, Madrid, Cívitas, 1997, pp. 365-393.

Laporta, M.H., "El Dolo y su determinación en Casación. Normatización y ubicación estructural en una concepción personal del injusto", Lexis Nexis, 2007. 
Santiago Roldán

Nino, C.S., Los límites de la responsabilidad penal: Una teoría liberal del delito, Buenos Aires, Astrea, 1980.

Nino, C.S., Introducción a la filosofía de la acción humana, Buenos Aires, Eudeba, 1987.

Nino, C.S., Introducción al análisis del derecho, Buenos Aires, Astrea, 1998.

Martínez Zorrilla, D., Conflictos constitucionales, ponderación e indeterminación normativa, Madrid, Marcial Pons, 2007.

Moreso, J.J., "Principio de legalidad y causas de justificación (Sobre el alcance de la taxatividad)", Doxa, 24, 2001, pp. 525-545.

Moreso, J. J., "Von Wright sobre 'ad impossibilia nemo tenetur", Doxa, 39, 2016, pp. 85-95.

Ortiz de Urbina G.I., "Martillos y Clavos: una respuesta a 'Normas penales y conflicto de deberes', de Juan Pablo Alonso”, Discusiones, 9, 2009, pp. 61-84.

Peralta, J.M., "Acerca de la función de las escalas penales, las consecuencias de una contradicción normativa y la responsabilidad en virtud de la actio illicita in causa", Discusiones, 9, 2009, pp. 131-160.

Righi, E. y Juárez, A.L., El régimen penal del cheque, Buenos Aires, Hammurabi, 2014.

Rodríguez, J.L., “La derrotabilidad de las normas jurídicas”, en Bayón, J. C. y Rodríguez, J. L. (eds.), Relevancia normativa en la justificación de las decisiones judiciales, Bogotá, Universidad Externado, 2003, pp. 67-101.

Rodríguez, J. L., "Derrotabilidad e indeterminación del derecho. Respuesta a Juan Carlos Bayón”, en Bayón, J. C. y Rodríguez, J. L. (eds.), Relevancia normativa en la justificación de las decisiones judiciales, Bogotá, Universidad Externado, 2003, pp. 209-262.

Rodríguez, J. L., Razonamiento y Decisión Judicial, La justificación de las decisiones judiciales en las democracias constitucionales, Buenos Aires, Ministerio de Justicia y Derechos Humanos de la Nación, 2017.

Ross, A., Sobre el derecho y la justicia, Buenos Aires, Eudeba, 1997.

Roxin, C., Derecho Penal, Parte General, Tomo I, Fundamentos, La estructura de la Teoría del Delito, Madrid, Civitas, 1997.

Sancinetti, M. A., Sistema de la teoría del error en el Código Penal argentino, Buenos Aires, Hammurabi, 1990. 
Sobre cheques y normas penales en conflicto. Balance de Discusiones 9 (2009)

Stern, R., “Does 'Ought' Imply 'Can'? And Did Kant Think It Does?”, Utilitas, 16, 1, 2004, pp. 42-61.

Verde, A., "Fundamento y límites de la impunidad por colisión de deberes en derecho penal”, Discusiones, 9, 2009, pp. 111-130.

von Wright, G. H., "Ser y deber ser", en Aarnio, A., Garzón Valdés, E., Uusitalo, J. (eds.), La normatividad del derecho, Barcelona, Gedisa, 1997, pp. 87-122.

Zaffaroni, E.R., Manual de Derecho Penal. Parte General, Buenos Aires, Ediar, 1999. 